Rumours of Japan's research on superconductors worries US

\section{Washington}

Rumours that Japan has launched lavish programmes of high-temperature superconductor research helped heighten the feeling of anxiety at the first US congressional hearing on the new materials, held last week. Representative Don Ritter (Republican, Pennsylvania) reported that Japanese government and industry may be spending " $\$ 4$ million a week" on superconductor research, against the $\$ 30$ million that Erich Bloch, director of the National Science Foundation, estimates that the US federal government will spend in the whole of this financial year.

The evidence of a Japanese representative, Shinroku Saito, president of the Technological University of Nagaoka, that Japan's Ministry of International Trade and Industry (MITI) had not actually launched a national programme since the new superconductors were discovered last November did little to ease the worries of witnesses testifying before the House Committee on Science, Space and Technology. Some still called for a US national programme to counter Japan's (even though it seems not to exist).

$\mathrm{H}$. Kent Brown, an engineering professor at Massachusetts Institute of Technology, fresh from a trip to Japan, confirmed that there is no national programme. But little comfort was to be had. He explained that Japanese corporations are so confident of winning the race to turn the new superconductors into commercial products that they could not be bothered to ask for MITI's help.

While the Japanese government may not be as deeply involved with industry as some US politicians imagine (see Nature 327, 356; 1987), the "vertical integration of Japanese industry, low cost capital and tremendous skill in processing of bulk ceramics" to which Ritter drew attention certainly must give US industry cause for concern. Witnesses at the hearing groped for a combination of basic and applied research that would break Japan's run of successes in automobiles, electronic goods and semiconductors.

All agreed that the United States still leads the world in basic research, but that transferring technology from laboratories to industry is the problem. William Graham, science adviser to the president, assured researchers that the president was behind them and offered a massive federal conference on the commercial applications of superconductivity (which will directly follow a conference with the same theme at Argonne National Laboratory in July). But congressmen questioning Graham were not satisfied that his good intentions would lead to actions.
A more radical suggestion, that one national laboratory be dedicated to the development of superconductors, came from Senator Pete Domenici (Republican. New Mexico). He is canvassing schemes for the formation of new consortia between a national laboratory and industry that would encourage technology transfer. Ritter agreed and called for a "coordinated 'Team America' strategy" bringing together industry, government and universities, and removing barriers to cooperation within industry by changes in anti-trust and patent laws.

Domenici has already introduced a bill to create a National Commission on Commercial and National Defense Applications of Superconductors. But IBM's Praveen Chaudhari argued last week that

government should help the whole technology development process by "appropriately supportive policies" rather than target specific technologies, and that it should limit direct investment to basic research and infrastructure. The "fruitful commercialization of technology", he said, is "the role and responsibility of private industry".

Despite the lavish praise they received, those carrying out basic research clearly had woes of their own. Paul Chu, whose discovery of superconductivity above $90 \mathrm{~K}$ fuelled the present excitement, worried about the health of the scientific community and stressed that important innovations could only come with support that left researchers "free to explore the unthinkable". But perhaps worrying about the international race that superconductor research has become, he added that "if breakthroughs could occur every day, our feeble hearts could probably not handle the stress".

Alun Anderson

\title{
Moscow Radio raises questions over missing Soviet scientist
}

\section{London}

THE case of Vladimir Aleksandrov, the Soviet computer specialist who disappeared from a peace conference in Madrid at the end of March 1985, is in the headlines again. In a broadcast on Moscow Radio's English-language service, his wife Alestina claimed that she still believes her husband to be alive somewhere, but that during his last trip to the United States before his disappearance he had encountered "difficulties" from the US security services. Furthermore, she said, the Spanish authorities had issued his visa for the peace conference only when it was half over.

Aleksandrov, who had worked on the Soviet model of 'nuclear winter', had visited the United States on a number of occasions. According to his wife's account, on his last trip a stamp had been placed in his passport indicating that he was not allowed to work with the computer which he and his US colleagues had previously used for nine months. He had to give a written promise that he would not speak at public conferences nor have any contact with the media, she said. Moreover, a security agent was "invariably present at his desk", his movements around the United States were monitored, and when he stayed for a night with a friend, he was informed by "alert security agents" that he had no right to leave his hotel room at night. All this, Mrs Aleksandrova said, forced his colleagues at the Lawrence Livermore Laboratory to apologize for the conditions in which he had to work.

The Moscow Radio announcer suggested that Mrs Aleksandrova's story about her husband's last US trip might "contain some hints at least as to where Aleksandrov should be looked for". But a former colleague, Georgii Stanchikov, was unwilling to accept this suggestion. Although the nuclear winter theory has opponents "and not only among scientists", he said, the theory was well known and no one would think that the removal of Aleksandrov would stop the debate. "I cannot name a person or organization that could be interested in the disappearance of Aleksandrov", Stanchikov concluded.

Colleagues of Aleksandrov from the Lawrence Livermore Laboratories confirm that, during his last visit there in January 1985 , security procedures were somewhat stricter than hitherto. But this was due to a general tightening-up of US restrictions and was not directed against Aleksandrov personally. They have no knowledge, however, of any official US prohibitions on his making public statements, and suggest that if any such restriction was imposed on his contacts with the media, it came not from the US authorities but from SCOPE, the environmental group which had sent him there to compare US and Soviet models for the nuclear winter, and which would not have wanted any premature leaking of this work. In fact, Aleksandrov gave at least two lectures during this visit, one at Oregon State University, and one in Los Angeles. Moreover, as on previous occasions, he stayed at the home of one of his US colleagues. Livermore scientists suggest that Mrs Aleksandrova's comments may be the result of some kind of misunderstanding.

Vera Rich 